\title{
FORGIVENESS: The Way to Holistic Well-Being
}

\author{
Suryalee Athwaria $^{1 *}$, A. K. Srivastava ${ }^{2}$
}

\section{ABSTRACT}

In an era of globalization where generations believe in lawsuits, it can sometimes seem like forgiveness is a concept from TretaYug (Era of Ramayan, the Hindu mythology) or Biblical times. However starting from last two decades of 20th century, developmental, social and clinical psychologists have begun to study the concept of forgiveness more intensively and scientifically(McCullough,2000).A wealth of research suggests that Forgiveness is a form of healing that considers the whole person- body, mind, spirit, and emotions- to achieve optimal health and well-being. Studies have found that the act of forgiveness can reap huge rewards for our health, lowering the risk of heart attack; improving cholesterol levels \& sleep; reducing pain, blood pressure, and levels of anxiety, depression and stress. Research points to an increase in the forgiveness-health connection as we age. Thus, field of psychology needs a proactive, positive approach emphasizing strengths, rather than continuing in the downward spiral of negativity trying to fix weaknesses.

Keywords: Forgiveness, Stress, Spiritual, Holistic Health, Well-Being.

“...the weak can never forgive. Forgiveness is an attribute of the strong." - (Mahatma Gandhi)

Though, Forgiveness is an ancient concept but historically it has been ignored as an area of study by social psychological theorists and scientists. Conflict, be it Man vs Man or Nature or Society or Self, the part of any doesn'”t just weigh down the spirit; it can also lead to physical health issues. Forgiveness is one of the relatively few universal human virtues (Peterson \& Seligman, 2000). All of the world"'s major religious traditions--Buddhism, Christianity, Hinduism, Islam, and Judaism- consider forgiveness a virtue to which human beings should aspire (McCullough \& Worthington, 1999). At the same time, forgiveness is among the least understood virtues and one of the most difficult to attain. Because minor abrasions occur in almost all human interactions, most people are practiced forgivers of individual offenses. Even under conditions of violence, war, and inhumane treatment, forgiveness is frequently practiced. Glynn (1994) observed that one explanation for the successful formation of the European Economic Union is forgiveness. Collectively speaking, the French,

\footnotetext{
${ }^{1}$ Research Fellow, Dept. Of Psychology, Banaras Hindu University, Varanasi, U.P., India

${ }^{2}$ Professor, Dept. Of Psychology, Banaras Hindu University, Varanasi, U.P., India

*Responding Author

(C) 2016, S Athwaria, A K Srivastava; licensee IJIP. This is an Open Access Research distributed under the terms of the Creative Commons Attribution License (http://creativecommons.org/licenses/by/2.0), which permits unrestricted use, distribution, and reproduction in any Medium, provided the original work is properly cited.
} 


\section{FORGIVENESS: The Way to Holistic Well-Being}

Dutch, and British forgave the Germans for the atrocities of World War II, as did other damaged nations. Likewise, the reciprocal forgiveness demonstrated by the United States and Japan after World War II helps explain the flourishing economic and social interchange that developed in subsequent decades. On the other hand, the lack of peace in certain war-torn areas of the world can be at least partly explained by the refusal of collectivities to forgive one another for past trespasses (Helmick \& Petersen, 2001).

In 1970, virtually no one had studied forgiveness scientifically. Forgiveness was seen as within the domain of religion, and (despite William James and early flirtation between psychology and religion) science was uneasy with religion. Only a few intrepid social scientists conducted isolated studies related to forgiving. Scientific study of forgiveness began in earnest only in the mid-1980s and has accelerated since that time. It started in the therapeutic community after the publication of a trade book, Forgive and Forget: Healing the Hurts We Don't Deserve, by Lewis Smedes (1984), to promote forgiveness in healing for problems in anger, lack of hope, depression, and trauma. In the mid-1980s, when most people thought about forgiveness, they associated it with religion. Even if people were not religious, common culture had imported the term forgiveness from religious usage. As society became more postmodern and multicultural, though, forgiveness broke free of the confines of religious communities and even religious connotation.

As more attention has been paid to the study of forgiveness both in popular culture and in science, more questions have arisen about what it is and how it develops, whether it is always beneficial, whether it can be iatrogenic or induced, and how we might help people forgive if they wish to forgive. As some questions have been answered, new questions have arisen. The depth of our lack of understanding of what forgiveness is and what its limits are has become more obvious. (Worthington, 2005). Thus, the aim of review is to explore the connections between forgiveness and physical, mental, and spiritual health, positivity resulted from the act of forgiveness, association between mental health issues such as anxiety and depression and un-forgiveness.

\section{FORGIVENESS: THEORETICAL FRAMEWORK}

Psychological scientists offered various definitions of forgiveness in the past two decades. In recent years, researchers generally agree that forgiveness is distinct from other ways of dealing with personal insult or injury. Most scholars agree that forgiveness occurs when an offended party chooses to abandon resentment, negative judgment, bitterness, and indifferent behavior in response to an offense (Enright, et al., 1992). Those negative emotions and attitudes are replaced by positive emotions, affirmative motivations, and prosocial behavior toward the offender (Enright \& Coyle, 1998; McCullough, Pargament, \&Thoreson, 2000). Forgiveness, then, is a conscious choice to replace negativity with positivity, and it is inherently social since it occurs in relationship to other individuals, not to inanimate objects. It is replacing negative thinking, action, and feelings with more positive thinking, action, and feelings (Enright \& Coyle, 1998).

Forgiveness is a process of removing an unpleasant and durable complex mental state, which has been called un-forgiveness (Enright, 2001; Worthington, 2006). ). Un-forgiveness incorporates a complex of negative emotions, negative thoughts, negative motivations, and avoidance behavior focused on the offender and the transgression. The negative emotions are primarily not only the feelings of anger, 


\section{FORGIVENESS: The Way to Holistic Well-Being}

bitterness, and resentment, but also include fear of future harm. McCullough (2003) and various collaborators have suggested that forgiveness is a redirection of motivations. They have defined forgiveness as a redirection in negative motivations, which is also accompanied by more conciliatory motivations toward the transgressor. Wade \& Worthington (2003) found that Emotional forgiveness which is a replacement of negative, unforgiving emotions with positive, other-oriented emotions is the key to neutralize negative feelings. At first, the positive emotions neutralize some negative emotions, resulting in a decrease in negative emotions. However, once the negative emotion is substantially eliminated, positive emotions can be built.

Although controversy surrounds the definition of forgiveness by Enright et al. (1992), psychologists generally agree about some core elements of forgiveness. For example, most psychologists agree that forgiveness does not imply pardoning (granted only by a representative of society, such as a judge) forgetting (removing awareness of the offence from consciousness; to forgive is more than just not thinking about the offence), condoning (failing to see the action as wrong and in need of forgiveness), or excusing offenses (not holding the person or group responsible for the action), and forgiveness does not necessarily imply reconciliation, trust, or release from legal accountability. Neither is forgiveness the same as reconciling a damaged relationship or restoring offenders to their former status (Sutton, 2010). Instead, many psychologists contend that forgiveness involves a conscious decision while acknowledging the seriousness of the wrong-to release or forego bitterness and vengeance (Enright, Freedman, \& Rique, 1998). Forgiveness is sometimes described as an altruistic gift (Smedes, 1984; Worthington, 1998b), one given freely in spite of not being deserved by offenders.

The construct of forgiveness has its historical roots in philosophy and theology, but can also be a part of contemporary social science. Some researchers regard it as an intrapersonal phenomenon in mentality, while others provide an interpersonal interpretation. In interpersonal relationships, forgiveness from one party toward the other that has exhibited transgression, betrayal, and/or other harmful actions is a requisite to the restoration of harmony in the relationship (Finkel et al., 2002), and should be the initial step in rebuilding trust (Chung \& Beverland, 2006; Schoorman, Mayer, \& Davis, 2007). Factors influencing interpersonal forgiveness can fall into social cognitive factors (empathy, attribution), factors related to transgressions (apology), relational factors (relationship satisfaction, commitment), and personality factors (agreeableness) (Fincham et al., 2002; Finkel et al., 2002; McCullough et al., 1998).

Certain authors (Worthington, 2000; Enright and the Human Development Group, 1994) have argued that forgiveness is exclusively an intrapsychic phenomenon. It occurs only within a single individual and is not a social phenomenon. While others (Pargament \& Rye, 1998; Baumeister, Exline, \& Sommer, 1998) indicate that both social and psychological dimensions exist. In the case of the former scholars, forgiveness is distinguished from reconciliation, meaning a re-establishment of a relationship between two parties. One can forgive, they assert, without wanting to re- stablish a relationship with the offender or without having the relationship return to normal. Forgiveness still requires abandoning negative affective and behavioral approaches. Trust may not be present, but the motives of the forgiver are toward goodness for the offender. Our approach to forgiveness, then, is as a concept with two core dimensions: an intrapsychic dimension and an interpersonal or social dimension. Forgiveness occurs when a transformation occurs within an individual as well as when the relationship between the victim and the perpetrator is changed.

(C) The International Journal of Indian Psychology, ISSN 2348-5396 (e)| ISSN: 2349-3429 (p) | 


\section{FORGIVENESS: The Way to Holistic Well-Being}

"In a nutshell, then, forgiveness may be best understood as having two distinct dimensions: It is both an internal mental/emotional state and an Inter-personal act. It can be a process that goes on entirely inside the mind of the victim, or it can be a transaction that occurs between two people, even without much in the way of inner processing”(Baumeister, Exline, \& Sommer, 1998: 86).

Studies have found that some people are just naturally more forgiving. Consequently, they tend to be more satisfied with their lives and to have less depression, anxiety, stress, anger and hostility. Despite misconceptions associating forgiveness with weakness or timidity, to truly forgive is an indication of remarkable strength and discipline. We should apply the act of Forgiveness to our daily lives because it may hold ample of spiritual and holistic health benefits.

\section{Forgiveness, Health \& Well-Being}

Well-being is a comprehensive term for the psychological, physical, social, or economic state of an individual or group (Scott et al., 2014; Diener 2009; Malhotra 2006; Sirgy\& Lee 2006). A major proposition in psychology is that well-being is not simply the lack of mental illness (Seligman \& Csikszentmihalyi, 2000). Seligman (2011), in PERMA model of flourishing, defined psychological well-being in terms of five domains: positive emotions (P), engagement $(\mathrm{E})$, relationships $(\mathrm{R})$, meaning $(\mathrm{M})$, and accomplishment $(\mathrm{A})$. The potential advantages of forgiveness are putatively observed as "holistic medicine" in the quest for optimal health and wellbeing. Thus, the prospective and possible benefits of Forgiveness are localized in the areas of physical, mental, relational, and spiritual health.

Forgiveness might affect peopleees physical health because it appears to decrease intrapersonal stress and the harmful emotions of persistent anger; it is not surprising that forgiveness is linked to better general health. Thus, speculations of positive outcomes are made regarding forgiveness. Although there is scarcity of research indicating direct association of forgiveness with improved physical health, still there are scores of researches showing direct positive relationship between forgiveness and physical health(Lawler et al, 2005, Witvliet et al, 2001). Researches have showed that a frequently unforgiving person might experience disorders of the cardiovascular or immune system. If we extend the findings from related literatures we might come to the conclusion that un-forgiveness has a negative impact on physical health. Un-forgiveness is stressful and makes people feel hostile toward transgressors (Witvliet, Ludwig, \& Vander Laan, 2001)while imagination of forgiving transgressors showed improvement in functioning of the cardiovascular system (measured by heart rate and blood pressure) and sympathetic nervous system, since forgiving results in substitution of positive emotions for negative emotions.

Toussaint, Williams, Musick, and Everson (2001) published results from a national survey suggesting that in elderly people, forgiveness was associated with fewer negative health symptoms. People over 45 years of age who had forgiven others reported greater satisfaction with their lives and were less likely to report symptoms of psychological distress, such as feelings of nervousness, restlessness, and sadness. The anticipation is that physical health will be negatively affected if people are chronically unforgiving and positively affected if they practice regular forgiveness. The act of forgiving reduces hostility and anger 


\section{FORGIVENESS: The Way to Holistic Well-Being}

(Bono \& Mc Cullough, 2004). Miller et al. (1996) reported Forgiveness to be associated with decrease in coronary problems and results in lower rate of premature deaths.

Forgiveness aids psychological healing through positive changes in affect (West, 2001). It can be said that Forgiveness and un-forgiveness might also affect mental health and well-being. At a minimum, it seems obvious that people who are unforgiving experience more anger and depression. Forgiveness might be associated with improved spiritual health. It restores a victimes sense of personal power (GobodaMadikizela, 2002; Fincham, Hall \& Beach, 2005) and improves physical and mental health (Toussaint \& Webb, 2005). A 2005 Journal of Behavioral Medicine study showed that forgiveness is associated with a whole range of health measures, including medications taken, sleep quality and fatigue.

A study (Lawler-Row \&Piferi, 2006) looked at seniors and found forgivingness related to levels of stress, well-being, and depression. Seybold et al (2001) observed that those high on forgiveness were healthier showing lower anxiety, anger and depression, lower hematocrit and W.B. counts. Moreover, these persons also had lower inclination towards alcohol and cigarette use (Lawler, et al, 2005), a more direct evidence of association between forgiveness and health. The authors found level of forgivingness was linked to successful aging, which included the mastery of the environment, relationships with others, purpose in life, and personal growth and acceptance. Earlier research on forgiveness and measures of health showed that forgiveness in general is positively associated with better health in terms of the heart, hormones, and immune system. A 2011 study of married couples in the journal of Personal Relationships, showed that when the victim in the situation forgave the other person, both experienced a decrease in blood pressure.

Additional studies using highly sophisticated imaging equipment to detect changes in brain functioning associated with forgiveness suggest potential for better understanding the link between forgiveness, mental states, and general health (Worthington et. al., 2007).People who forgive more readily are less likely to be depressed and anxious, and more likely to be happy. These physical and psychological qualities of forgiveness could all be key factor in predicting a longer life. The way we respond when we feel wronged, or when we seek even forgiveness of our-self, has a variety of health-boosting effects. Despite misconceptions associating forgiveness with weakness or timidity, truly forgiving is an indication of remarkable strength and discipline.

\section{CONCLUSION AND FUTURE RESEARCH}

New research suggests that forgiveness tends to be positively associated with over all well-being and desirable relationship outcomes. As, Forgiveness can benefit peoplees physical health and psychological well-being; forsaking a grudge may free a person from hostility and all its unhealthy consequences. People can deal with injustices and wrong doings in many ways. They don't have to decide to forgive, and they don't necessarily need to change their emotions. But if they don"et change their response, unforgiveness can take its toll on physical, mental, relational, and even spiritual health. So, when we forgive someone, we make the choice to give up our desire for revenge and feelings of resentment. Instead of revenge, resentment \& judgement, we show generosity, tolerance and kindness. Also, in many publications indirect association of forgiveness is established with commitment (Karremans \& Lange et al, 2003), reduction in negative effect, reduction in stress and good social skills (Lawler et al, 2005) as 


\section{FORGIVENESS: The Way to Holistic Well-Being}

mediating variable. So there is need for more rational studies establishing more direct relationship between forgiveness and negative effects. Further research in this area is warranted, if we consider the immense significance of forgiveness in conflict management particularly with regard to international and organizational conflicts. Fortunately, forgiveness is found to be tillable and then can be practices through different strategies, including developing empathy. The overall intent of the article is to generate some positive thinking and excitement for the OB field and "hopefully" stimulate some new theory building, research, and effective application.

\section{Acknowledgments}

The authors appreciate all those who participated in the study and helped to facilitate the research process.

\section{Conflict of Interests}

The authors declared no conflict of interests.

\section{REFERENCES}

Aquino, K., Tripp, T. M., \& Bies, R. J. (2001). How employees respond to personal offense: The effects of victim and offender status on revenge and reconciliation in the workplace. Journal of Applied Psychology, 86, 52-59.

Baumeister, R. F., Exline, J. J., \& Sommer, K. L. (1998). The victim role, grudge theory, and two dimensions of forgiveness. In E. L. Worthington, Jr. (Ed.), Dimensions of forgiveness: Psychological research and theological perspectives (pp. 79-104). Philadelphia: Templeton Foundation Press.

Berry, J. W., Worthington, E. L., Parrott, L., O’Connor, L. E., \& Wade, N. G. (2001). Dispositional forgiveness: Development and construct validity of the transgression narrative test of forgiveness (TNTF). Personality and Social Psychology Bulletin, 27, 1277-1290.

Chung, E., \& Beverland, M. B. (2006). An exploration of consumer forgiveness following marketer transgressions. Advances in Consumer Research, 33, 98-99.

Diener, E. (2009). The Science of Well-being. New York: Springer.

Enright, R. D. \& Coyle, C. (1998). Researching the process model of forgiveness within psychological interventions. In E. L. Worthington (Ed.), Dimensions of Forgiveness (pp.139-161). Philadelphia: Templeton Foundation Press.

Enright, R. D. (2001). Forgiveness is a choice: A step-by-step process for resolving anger and restoring hope. Washington, DC: American Psychological Association.

Enright, R. D., \&The Human Development Study Group (1994). Piaget on the moral development of forgiveness: Identity and reciprocity. Human Development, 37, 63-80.

Enright, R. D., Eastin, D. L., Golden, S., Sarinopoulos, I., \& Freedman, S. (1992). Interpersonal forgiveness within the helping professions: An attempt to resolve differences of opinion. Journal of Counseling and Values, 36, 84-103. 


\section{FORGIVENESS: The Way to Holistic Well-Being}

Enright, R. D., Freedman, S., \& Rique, J. (1998). The psychology of interpersonal forgiveness. In R. D. Enright \& J. North (Eds.), Exploring forgiveness (pp. 46-63). Madison: University of Wisconsin Press.

Exline, J. J., Worthington, E. L. Jr., Hill, P. C., \& McCullough, M. E. (2003). Forgiveness and justice: A research agenda for social and personality psychology. Personality and Social Psychology Review, 7, 337-348.

Fincham, F. D. (2009), Forgiveness: Integral to close relationship and inimical to justice? Virginia Journal of Social Policy and the law, 16, 358-384.

Fincham, F. D., Hall, J.H. \& Beach, S.R.H. (2005). Til lack of forgiveness do us part: Forgiveness in marriage? In E.L. Worthington (Ed.), Handbook of forgiveness(pp. 207226). New York: Routledge.

Fincham, F. D., Paleari, F. G., \& Regalia, C. (2002). Forgiveness in marriage: The role of relationship quality, attributions, and empathy. Personal Relationships, 9, 27-37.

Finkel, E. J., Rusbult, C. E., Kumashiro, M., \& Hannon, P. A. (2002). Dealing with betrayal in close relationships: Does commitment promote forgiveness? Journal of Personality and Social Psychology, 82, 956-974.

Folger, R., \&Cropanzano, R. (1998). Organizational justice and human resource management. Thousand Oaks, CA: Sage.

Glynn, P. (1994). Toward a politics of forgiveness. American Enterprise, 5, 48-53.

Greenberg, J.,\&Cropanzano, R. (Eds.). (2001). Advances in organizational justice. Palo Alto, CA: Stanford University Press.

Harris, D.H.S., \& Thoresen, C.E. (2005). Forgiveness, Unforgiveness, health, and disease. In E.L.Worthington, Jr. (Ed.), Handbook of Forgiveness (pp.321-334). New York: Brunner Routledge.

Helmick, R. G., \& Petersen, R. L. (2001). Forgiveness and Reconciliation: Religion, Public Policy, and Conflict. Philadelphia: Templeton Foundation Press.

Karremans, J.C., Van Lange, P.A.M., Ouwerkerk, J.W., \& Kluwer, E.S. (2003). When forgiving enhances psychological well-being: The role of interpersonal commitment. Journal of Personality and Social Psychology, 84, 1011-1026.

Lawler, K.A., Younger, J.W., Piferi, R.L., Jobe, R.L., Edmondson, K.A., \& Jones, W.H. (2005). The unique effects of forgiveness on health: An explosion of pathways. Journal of Behavioural Medicine, 28, 157-167.

Lawler-Row, K. A.,\& Piferi, R. L. (2006). The forgiving personality: Describing a life well lived? Personality and Individual Differences, 41, 1009-1020.

Malhotra, N. K. (2006). Consumer well-being and quality of life: An assessment and directions for future research. Journal of Macromarketing, 26, 77-80.

McCullough, M. E., \& Worthington, E. E. (1999). Religion and the forgiving personality. Journal of Personality, 67, 1141-1164. 


\section{FORGIVENESS: The Way to Holistic Well-Being}

McCullough, M. E., Fincham, F. D., \& Tsang, J. A. (2003). Forgiveness, forbearance, and time: The temporal unfolding of transgression-related interpersonal motivations. Journal of Personality and Social Psychology, 84, 540-557.

McCullough, M. E., Pargament, K. I., \& Thoreson, C. (2000). Forgiveness: Theory, Research, and Practice. New York: Guilford.

Pargament, K. I., \& Rye, M. S. (1998). Forgiveness as a method of religious coping. In E. L. Worthington (Ed.), Dimensions of Forgiveness: Psychological Research and Theological Perspectives(pp. 59-78). Philadelphia: Templeton Foundation Press.

Sandage, S. J., Worthington, E. L., Hight, T. L., \& Berry, J. W. (2000). Seeking forgiveness: Theoretical context and initial empirical study. Journal of Psychology and Theology, 28, 21-35.

Schoorman, F. D., Mayer, R. C., \& Davis, J. H. (2007). An integrative model of organizational trust: Past, present, and future. Academy of Management Review, 32, 344-354.

Scott, K., Diane, M. M., \& Schouten, J.W. (2014). Marketing and the New Materialism. Journal of Macromarketing, 34, 282-290.

Seligman, M. E. P. (2011). Flourish. New York, NY: Simon \& Schuster.

Seligman, M. E. P., \& Csikszentmihalyi, M. (2000). Positive psychology: An introduction. American Psychologist, 55, 5-14.

Sirgy, M. J. \& Lee, D. (2006). Macro measures of consumer well-being (CWB): A critical analysis and a research Agenda. Journal of Macromarketing, 26, 27-44.

Smedes, L. B. (1984). Stations on the journey from forgiveness to hope. In E. L. Everett (Ed.), Dimensions of Forgiveness: Psychological Research and Theological Perspectives (pp. 41-354). Philadelphia: Templeton Foundation Press.

Sutton, G. W. (2010). The psychology of forgiveness, reconciliation, and restoration: Integrating traditional and Pentecostal theological perspectives with psychology. In M. W. Mittelstadt\& G. W. Sutton (Eds.), Forgiveness, reconciliation, and restoration: Multidisciplinary studies from a Pentecostal perspective (pp. 125-144). Eugene, OR: Pickwick Publications.

Toussaint, L. L., Williams, D. R., Musick, M. A., \& Everson, S. A. (2001). Forgiveness and health: Age differences in a U.S. probability sample. Journal of Adult Development, 8, 249-257.

Toussaint, L., \& Webb, J. R. (2005). Theoretical and empirical connections between forgiveness, mental health and well-being. In E.L. Worthington (Ed.), Handbook of forgiveness(pp. 349-362). New York: Routledge.

Wade, N. G., \& Worthington, E. L., Jr. (2003). Overcoming interpersonal offenses: Is forgiveness the only way to deal with unforgiveness? Journal of Counseling and Development,81, 343-353.

West, W. (2001). Issues relating to the use of forgiveness in counselling and psychotherapy. British Journal of Guidance and Counselling, 29, 415-423. 


\section{FORGIVENESS: The Way to Holistic Well-Being}

Witvliet, C. V. O., Ludwig, T. E., \& Vander Laan, K. L. (2001). Granting forgiveness or harboring grudges: Implications for emotion, physiology, and health. Psychological Science, 121,117-123.

Worthington, E. L. Jr., Witvliet, V. O. C., Pietrini, P., Miller, A. J. (2007). Forgiveness, health, and well-being: A review of evidence for emotional versus decisional forgiveness, dispositional forgivingness, and reduced forgiveness. Journal of Behavioral Medicine, 30, 291-302. doi: 10.1007/s10865-007-9105-4.

Worthington, E. L., Jr. (1998b). The pyramid model of forgiveness: Some interdisciplinary speculations about unforgiveness and the promotion of forgiveness. In E. L. Worthington, Jr. (Ed.), Dimensions of forgiveness (pp. 107-137). Philadelphia: Templeton.

Worthington, E. L., Jr. (2003). Forgiving and reconciling: Bridges to wholeness and hope. Downers Grove, IL: Inter Varsity Press.

Worthington, E. L., Jr. (2006). Forgiveness and reconciliation: Theory and application. New York: Brunner-Routledge.

Worthington, E. L., Jr., \& Scherer, M. (2004). Forgiveness is an emotion-focused coping strategy that can reduce health risks and promote health resilience: Theory, review, and hypotheses. Psychology and Health, 19, 385-405.

Worthington, E. L., Jr., \& Wade, N. G. (1999). The social psychology of unforgiveness and forgiveness and implications for clinical practice. Journal of Social and Clinical Psychology, 18, 385-418.

Worthington, E. L., Kurusu, T. A., Collins, W., Berry, J. W., Ripley, J. S., \& Baier, S N.(2000). Forgiveness usually takes time: A lesson learned by studying interventions to promote forgiveness. Journal of Psychology and Theology, 28, 3-20.

Worthington, E. L.,Jr. (2005).Handbook of forgiveness. New York: Hove-Routledge.

How to cite this article: S Athwaria, A Srivastava (2016), FORGIVENESS: The Way to Holistic Well-Being, International Journal of Indian Psychology, Volume 3, Issue 4, No. 67, ISSN:2348-5396 (e), ISSN:2349-3429 (p), DIP:18.01.177/20160304, ISBN:978-1-365-39397-6 